University of Nebraska - Lincoln

DigitalCommons@University of Nebraska - Lincoln

Faculty Publications, Department of Psychology

Psychology, Department of

April 1972

\title{
The Role of Anxiety and Arousal Attribution in Cheating
}

Richard A. Dienstbier

University of Nebraska-Lincoln, rdienstbier2@unl.edu

Follow this and additional works at: https://digitalcommons.unl.edu/psychfacpub

Part of the Psychiatry and Psychology Commons

Dienstbier, Richard A., "The Role of Anxiety and Arousal Attribution in Cheating" (1972). Faculty

Publications, Department of Psychology. 217.

https://digitalcommons.unl.edu/psychfacpub/217

This Article is brought to you for free and open access by the Psychology, Department of at DigitalCommons@University of Nebraska - Lincoln. It has been accepted for inclusion in Faculty Publications, Department of Psychology by an authorized administrator of DigitalCommons@University of Nebraska - Lincoln. 


\section{The Role of Anxiety and Arousal Attribution in Cheating}

\author{
Richard A. Dienstbier ${ }^{1}$ \\ University of Nebraska-Lincoln
}

Previous research indicated that anticipating arousal symptoms (rather than benign) from a placebo pill reduced inhibiting emotion in men, resulting in more cheating. The effect did not occur for women. Using 180 males, Study I tested whether the placebo effect was due to mere attention to arousal symptoms, or whether attribution to the pill was required. In the placebo- attribution condition the arousal placebo facilitated cheating $(p<$ $.02)$. The effect did not occur for symptom-attention controls who received no pill, and the conditions differed $(p<.02)$. Study II tested whether women failed to respond to the placebo manipulation due to higher anxiety. Under one of four stress levels, each of 240 women received the benign or arousal placebo. More cheated with the arousal placebo only under low stress $(\mathrm{p}<.035)$, and stress conditions differed $(p<.025)$. The interaction of attribution manipulations with the conflicting emotions of the cheating situation is discussed.

Research by Schachter and Latane (1964) indicated that adrenalin injections in both rats and psychopathic criminals facilitated avoidance learning. A complementary study by Schachter and Ono (Schachter \& Latane, 1964) indicated that reducing arousal through the administration of the tranquilizer chloropromazine increased cheating (reduced avoidance) by college student subjects when compared with a placebo control group. Both studies were interpreted as supporting the hypothesis that emotional arousal enhances avoidance behavior.

Using an arousal symptom manipulation similar to that of Nisbett and Schachter (1966), Dienstbier and Munter (1971) investigated the influence on cheating behavior of false information concerning the source of emotional arousal. It was hypothesized that emotional arousal experienced as fear or guilt concerning the transgression is a signal of danger or conflict, and that

${ }^{1}$ The author is grateful to Monte M. Page for helpful comments on the original draft of this paper, and to Keith Stolzenbach for being the experimenter of Study II. Requests for reprints should be sent to Richard A. Dienstbier, Department of Psychology, University of Nebraska-Lincoln, Lincoln, Nebraska 68508. experiencing such emotions inhibits cheating. But if a tempted individual could be made to believe that his arousal was pill-induced, he might not label or experience that natural arousal as an inhibiting emotion; being freed from inhibition he might cheat. The issue focused not on the inhibiting effects of arousal level per se, but upon the interpretations or attribution of that arousal. Subjects received written information on the potential side effects of a placebo pill. Through that manipulation, half the subjects anticipated side effects relevant to emotional arousal while half expected benign or arousal irrelevant side effects. Subjects were later given a difficult test presented as an important task used to fill the interval "before the pill took effect." They were subsequently allowed to see that they had failed, and were told that they would, therefore, be asked to go before a "board of psychologists" to discuss their "subnormal performance." Subjects were then given an opportunity to cheat.

As predicted, subjects cheated significantly more when anticipating arousal-related side effects from their pill, with $49 \%$ cheating in that "arousal" placebo condition against only $27 \%$ cheating in the "benign" placebo condition. That effect was due almost totally to the men subjects; the women seemed unresponsive to the placebo side effects manipulations. Only $17 \%$ of the males cheated in the benign symptom group, while $56 \%$ of the arousal group men cheated. The comparable figures for women of $36 \%$ benign cheaters and $42 \%$ arousal cheaters indicated no comparable effect. Several issues raised by that research required clarification.

\section{Issues from the Male Data}

The first issue was whether the side effects labeling process affected cheating in the hypothesized manner. It seemed possible that merely attending to arousal symptoms could reduce one's capacity to experience arousal symptoms as emotion. Since several other researchers had used attribution paradigms similar to that of the Dienstbier and Munter (1971) research, this question was equally relevant to the interpretation of that research, reviewed below.

Nisbett and Schachter (1966) measured the shock-induced pain tolerance of women subjects. Subjects in the low anxiety group (not made overly fearful of the shock) who anticipated pill-induced arousal tolerated significantly more shock than their benign placebo counterparts. The results indicated that the attribution of the shock-induced arousal to the placebo reduced feelings of fear or anxiety, allowing the increased shock tolerance. The placebo effect was not replicated in the high anxiety conditions, in which subjects were made more fearful of the consequences of the shock. Ross, Rodin, and 
Zimbardo (1969) manipulated fear in a paradigm in which loud noise was substituted for the placebo of the Nisbett and Schachter (1966) study. Half of their subjects were led to anticipate arousal symptoms from the noise, while half anticipated benign symptoms. Subjects anticipating noise-induced arousal indicated reduced fear by working less on a task which could reduce the likelihood of their being shocked. Storms and Nisbett (1970) found that insomniac subjects who had been told to expect arousal from their (placebo) pills reported that they slept earlier than subjects who anticipated relaxation from their pills. Those subjects apparently felt less disturbed by emotional arousal associated with apprehension over not being able to sleep. The opposite effect was anticipated and achieved for the relaxation placebo group.

In none of these studies was the issue of symptom attention versus attention plus attribution investigated. The first study of this paper was an attempt to answer that question experimentally, and to serve as a replication for men of the Dienstbier and Munter (1971) cheating results. It was predicted that the attribution manipulation would prove vital, and that subjects not given a placebo pill but whose attention was drawn to comparable physiological "symptoms" would not cheat differentially in the arousal and benign conditions.

\section{Issues from the Female Data}

The second issue raised by the Dienstbier and Munter (1971) research concerned why the placebo side effects manipulation was ineffective for women. It suggested that the experimental procedure created a greater overall anxiety level for women, and that the anxiety over the necessity of "going before a board of psychologists" with test failure so overwhelmed the women that they failed to attend to the information concerning the expected pill side effects. The literature on sex differences in anxiety tends to support the notion of greater female anxiety. In her book The Development of Sex Differences, Maccoby (1966) listed 31 studies of sex differences utilizing anxiety measures ranging from paper and pencil tests to observational, behavioral, and physiological indices. Of those 31 studies, 18 indicated greater anxiety on the part of girls or women in comparison to only two studies finding greater anxiety for boys (and 11 finding no differences).

The anxiety explanation also seemed to fit well with data obtained with women subjects by Nisbett and Schachter (1966) who achieved attribution effects only for their low anxiety subjects.

The second study presented in this paper was designed to test the hypothesis that the arousal placebo manipulation would be effective in in- creasing women's cheating rates under conditions of reduced anxiety or low stress; Study II was also a partial replication of the Dienstbier and Munter (1971) study.

\section{STUDY I}

Method

Subjects. The 180 subjects were all first semester freshmen men who had volunteered to participate in a study on the effects "of a vitamin supplement on visual perception" in order to partially fulfill the research participation option of the basic psychology course. The use of freshmen subjects and the completion of the study by the beginning of the sixth week of the semester was accomplished to minimize subject sophistication. This study was the first psychology experiment participation for most of the subjects.

Design. Each group of subjects was randomly assigned to either a Replication Condition, which followed closely the design of the Dienstbier and Munter (1971) paradigm, or assigned to a Control Condition, in which subjects received no pill and were told that they were control subjects. Within each of those two major conditions and within each subject group, subjects were randomly assigned to either Arousal Symptom Conditions or to Benign Symptom Conditions.

Replication Condition procedure. Participating in groups of 6 to 10, subjects were seated in a row of booths so they could see the experimenter, but so that they could not see each other's desk surfaces.

Each subject received a booklet which first introduced the "vitamin supplement" and its side effects. Each subject also received a placebo pill (gelatin) and water. Subjects in the arousal pill condition read that they might experience "a pounding heart, hand tremor, sweaty palms, a warm or flushed face, and a tight or sinking feeling in the stomach" (after Nisbett \& Schachter, 1966). Benign pill condition subjects were told of side effects irrelevant to arousal, including yawning and eye-blink rate changes, and "tired or heavy eyes."

Subjects were then told that there would be a 15-min delay "to allow the pill to take effect," during which they would take a vocabulary test "under development by the Educational Psychology Department." Subjects were told that even though the test was still being standardized, it was predictive of college performance; a minimum score of 20 (out of 30) right was associated with future college success. The developers of the test would want to see any student who scored less than 20. Subjects were instructed to enter their names and phone numbers on their answer sheets to facilitate that contact.

Presentation of the autokinetic effect followed the vocabulary test in order to convince subjects of the pill's effects. Previous research (Dienstbier \& Munter, 1971) had indicated that more than $95 \%$ of the subjects saw the autokinetic light move when exposed to it in three $30-\mathrm{sec}$ periods as used in this procedure. When the room lights were turned on the subjects were allowed to see (without explicit mention by the experimenter) that the autokinetic light source could not have moved.

After the autokinetic phase, subjects were told to look over the side effect rating form provided as part of their "vitamin supplement" booklet. This procedure was designed to increase the saliency of the side effect, and usually resulted in that side effect list being left face-up before the subject for the duration of the cheating period. 
Subjects were then told that there would be $8 \mathrm{~min}$ before the side effects form was to be filled out, and that they could use that time to look over the correct answers; they were shown where to find those answers in their vocabulary test booklet. They were told that, since machine grading the answers had been a problem, they should make sure that their answers were cleanly erased and darkly marked, but they were warned "do not change any answers." This procedure gave each subject an excuse to use his pencil during the ensuing cheating period. After about 2 min of the cheating period had elapsed, the experimenter answered the desk phone which he could ring with a hidden button. In the ensuing phone monologue, the experimenter agreed to continue the conversation in another room. The experimenter then left the room, leaving no one in attendance, "to take the call on the other extension." This lack of any attendant in the room for a time during the cheating period probably accounts for the increase in the cheating base rate in the present study over that for men in the original cheating study (in which a person was always in attendance). The benign condition increased from $17 \%$ men cheaters in the Dienstbier and Munter (1971) study to $45 \%$ in the comparable Replication Condition of this study. Subjects were cautioned to maintain silence; experimenter checks indicated compliance. After a 3-min absence, the experimenter returned to the lab for the last 2 min of the cheating period.

Subjects were subsequently directed to finish their "vitamin supplement" booklet, including the side effect assessment form and the postexperimental forms. The postexperimental questionnaire directly assessed levels of suspiciousness concerning whether the pill "could have been a placebo," how great and what suspicions concerning the vocabulary tests existed, whether the subjects suspected any relationships between the pill side effects and the vocabulary test, and whether they believed the purpose of the study concerned cheating.

Subjects were then completely debriefed as to the nature and purpose of all aspects of the study, and were assured that their data would be completely confidential and would never be associated with their names. Subjects' normal responses to the extensive debriefing were very positive; subjects were then sworn to secrecy.

Control Condition procedure. Control Condition subjects were told that though they had come to the study on "vitamin supplements" they would not receive a pill. Instead, they would serve as a "comparison group" for the groups who did take the pill. It was explained that the only way to be certain that the side effects ratings by the "experimental" groups really reflected pill-induced changes was through comparisons with groups in exactly the same circumstances who had not had the "vitamin supplement." The importance of such "comparison groups" in the study was emphasized, and subjects were told that later when they would be asked to study the side effects rating forms and to rate their feelings, that it would be most important that they take the task seriously. Control Condition subjects were randomly assigned to rate either arousal or benign symptoms.

Since the Control Condition subjects were to do "exactly the same tasks as the pill groups in order to make later side effect ratings comparable," they were given the same instructions concerning the vocabulary test. They were not told about the autokinetic phase, since in the Control Conditions with no pill, its validation would have been inappropriate. They went directly from their vocabulary tests to the side effects saliency manipulations. They were told to study the side effects rating form to get an idea of what physiological symptoms were to be rated at the end of an 8-min waiting period. They were reminded of the importance of "really looking into" themselves, and asked to be- gin "now" to become sensitive to those feelings. The cheating session was then run exactly as with the Replication Conditions. This shortening of the experimental procedures by eliminating the autokinetic phase may have resulted in greater salience of the vocabulary test since subjects were not distracted by time and the autokinetic effect, and probably accounts for the cheating base rate (benign group) being higher than that for the Replication Condition subjects.

The final questionnaires and debriefing were comparable to the Replication Conditions. Cheating was assessed in the present study as in the Dienstbier and Munter (1971) research with a hidden pressure-sensitive paper. This procedure allows an exact count of answers changed.

\section{Results}

Of the 180 subjects, 13 were dropped for the following reasons: six indicated some hypothesis awareness; two failed to follow instructions; two got over 20 of the vocabulary answers right without cheating (and therefore had no need to cheat) ; three did not press hard enough on their vocabulary answer sheets to provide a readable second record on the pressure-sensitive paper. Three subjects with no readable second record who scored 20 or more right answers were retained in the data pool classified as cheaters. Data from all the author's cheating studies using this technique indicate that such a classification can be made with $92 \%$ certainty. Those three subjects were in the Replication Arousal, Control Arousal, and Control Benign Conditions. None of the six suspicious subjects had cheated, but had they been included in the analysis significance levels would not have changed appreciably.

As indicated in Table 1, the pattern of cheating differed greatly between the Replication and the Control Conditions, with the expectation of arousal side effects facilitating cheating in the Replication Condition but with no comparable Control Condition effect. In the Control Conditions, the cheating base rate (the Benign Condition) was higher, probably due to the increased salience of the vocabulary test as explained above. The pattern of cheating within the Replication Conditions is reversed with nonsignificantly less cheating in the arousal symptom group.

A chi-square test of interaction or heterogeneity (Snedecor, 1946, pp. 191) between the Replication and the Control Conditions indicates that the patterns of cheating are quite different (a chi-square statistic of 6.51 with 1 $d f$, significant at less than .02).

If cheating were defined as changing enough answers to reach the criterion of 20 right (so that the subject would not "have to go before the board"), there were no major or significant differences between arousal and benign symptom groups within either the Replication or the Control Conditions. In the Replication Conditions, seven subjects cheated to criterion in the Arous- 
TABLE 1

Classification of Men Subjects as Cheatersa and Noncheaters By Condition

\begin{tabular}{|c|c|c|c|c|}
\hline Condition & Cheaters & Noncheaters & $\begin{array}{l}\text { Percent } \\
\text { cheaters }\end{array}$ & $\begin{array}{c}\text { Probability } \\
\text { level }^{b}\end{array}$ \\
\hline \multicolumn{5}{|c|}{ Replication Conditions } \\
\hline Arousal & 29 & 12 & 70.7 & \\
\hline Benign & 18 & 22 & 45.0 & .02 \\
\hline \multicolumn{5}{|c|}{ Control Conditions } \\
\hline Arousal & 21 & 20 & 51.2 & \\
\hline Benign & 29 & 16 & 64.5 & NS \\
\hline
\end{tabular}

a Cheaters are defined as a person changing any answer after test completion.

${ }^{b}$ Probability levels are determined by the Fisher Exact Test (Hays, 1966) and represent one-tailed tests of the hypotheses.

al and six in the Benign Condition, while in the Control Conditions the comparable figures are five and nine. This failure to find significant differences within the Replication Condition is a partial failure to replicate the results of Dienstbier and Munter (1971) in which more (male) subjects cheated in the Arousal Conditions by either definition of cheating. The number of items changed by each cheating subject also did not differ significantly between conditions. The average number of changed answers per cheater in the various conditions are as follows: Replication Arousal, 5.4; Replication Benign, 7.8; Control Arousal, 6.4; Control Benign, 6.6.

\section{STUDY II}

\section{Method}

Subjects. Two hundred forty second-semester freshmen women subjects participated in this study in partial fulfillment of an experimental obligation associated with the basic psychology course. The rationale for choice of freshmen subjects, the 5-week time limit, and sign-up procedures were as described above for Study I.

Design. Four stress-level conditions were created which were identical except for the emphasis put upon the consequences of failure on the vocabulary test. Upon reporting to the lab, each subject group was randomly assigned to one of the four conditions with subjects within groups randomly assigned to arousal or benign placebo conditions. More subjects were run in the low anxiety groups to allow more accurate estimates of their lower cheating rates.

The condition of highest stress (Condition A) was essentially a replication of the design of the Dienstbier and Munter (1971) study. Although subjects in all four conditions were told that "few successful college students score less than 20, as freshmen," Condition A subjects were told to put their names and phone numbers on their answer sheets. They were told that in case any did score lower than 20 "the board of psychologists who have developed this test would like to question you about your subnormal performance."
In the condition of the second highest stress (Condition B), subjects were required to enter only their names to allow the board of psychologists "to compare your future performance in college with your test score . . . in order to check out the predictive accuracy of the test."

The condition of third highest stress (Condition C) required only the subjects' names on the answer paper, "just in case the board of psychologists decide that they want to compare your performance with your college entrance exam scores. . . . Basically, though, those psychologists are only interested in how freshmen do generally; they are not interested in your score as an individual."

The condition of least stress (Condition D) required no name on the answer paper. Subjects were informed that "although the board of psychologists who have developed this test is interested in how freshmen do here, they are not interested in your score as an individual."

Procedure. The procedures used in the four conditions were identical to those of Dienstbier and Munter (1971) and the Replication Condition of Study 1, above, with the exception that a modification of the cheating period was instituted. Using a desk phone rung by a hidden button, the experimenter carried on a muted 2-min monologue while remaining in the same room with the subjects.

\section{Results}

Of the 240 subjects, 34 were dropped for the following reasons: 8 indicated some hypothesis awareness; 6 failed to follow directions; 2 got over the criterion of 20 right without cheating; 18 marked their answers too lightly to detect cheating. The three subjects who scored over 20 but who had no readable second answer record were retained; they were in Conditions A Arousal, A Benign, and D Arousal, and were retained since their classification as cheaters could be made with $92 \%$ certainty. None of the eight suspicious subjects had cheated, but had they been retained, statistical significance levels would not have been altered appreciably.

The change in cheating pattern with stress level can be seen in Table 2 ; the arousal placebo facilitated cheating more in the low stress conditions. Although the reversal in Condition A with more cheating in the benign group cannot be explained within the frame of arousal attribution theory, the chi-square statistic of 1.07 (with $1 d f$, significant at .30) indicates a strong possibility that the reversal was a chance occurrence.

Prior to data collection it was planned to compare statistically the combined high stress Conditions A and B with the combined low stress Conditions $\mathrm{C}$ and D. Although the four stress levels were run to provide detailed information on the relationship of stress level to arousal attribution, the combination of the four groups into two resulted in numbers of subjects per condition comparable to those of Study I, and resulted in more accurate statistical tests. The remaining analyses are all between those combined conditions. 
TABLE 2

Classification of Women Subjects as Cheaters ${ }^{a}$ and Noncheaters BY Condition

\begin{tabular}{|c|c|c|c|c|}
\hline Condition & Cheaters & Noncheaters & $\begin{array}{l}\text { Percent } \\
\text { cheaters }\end{array}$ & $\begin{array}{c}\text { Probability } \\
\text { level }^{b}\end{array}$ \\
\hline \multicolumn{5}{|c|}{ Condition A (highest anxiety) } \\
\hline Arousal & 9 & 14 & 39.1 & \\
\hline Benign & 13 & 10 & 56.5 & NS \\
\hline \multicolumn{5}{|l|}{ Condition B } \\
\hline Arousal & 6 & 13 & 31.6 & \\
\hline Benign & 6 & 16 & 27.2 & NS \\
\hline \multicolumn{5}{|l|}{ Condition $\mathrm{C}$} \\
\hline Arousal & 11 & 18 & 37.9 & \\
\hline Benign & 6 & 19 & 24.0 & NS \\
\hline \multicolumn{5}{|c|}{ Condition D (lowest anxiety) } \\
\hline Arousal & 8 & 26 & 23.5 & \\
\hline Benign & 2 & 29 & 6.9 & 0.057 \\
\hline
\end{tabular}

a Cheaters are defined as a person changing any answer after test completion.

${ }^{b}$ Probability levels are determined by the Fisher Exact Test (Hays, 1966), and represent one-tailed tests of the hypotheses.

A chi-square test of interaction (Snedecor, 1946) between combined Conditions $\mathrm{A}$ and $\mathrm{B}$ and combined Conditions $\mathrm{C}$ and $\mathrm{D}$ indicated significance at below .025 (a one-tailed chi-square of 3.84 with $1 d f$ ). A Fisher Exact Test of the effect of the pill side effect instructions by cheating for combined Conditions $\mathrm{C}$ and D was significant at .032 . Only 12 cheaters changed enough answers to reach the criterion of 20 correct, with seven in Conditions A and B Arousal, against three in the Benign Conditions, and one each in the Arousal and Benign Conditions of combined Conditions C and D.

As in the Replication Conditions of Study I, cheaters did not change more answers in the Arousal Conditions than in the Benign Conditions. Cheaters changed an average of 4.0 answers in the Arousal Conditions of $\mathrm{A}$ and $\mathrm{B}$ against 4.3 in the Benign Conditions (NS) ; in Conditions C and D comparable figures of 3.9 and 4.0 were obtained (NS). Both Studies I and II thus indicate that although the number of individuals who become cheaters is influenced by the pill manipulations, the extent of cheating for each individual is not.

\section{DISCUSSION}

Study I

The data of Study I indicate arousal reduction, as evidenced by increased cheating, requires that the subject be given information about the source of his arousal. This assertion is based upon the assumption that the Control Condition subjects did not attend significantly less to their benign or arousal symptoms than did the Replication Condition subjects. Although this cannot be proven, control subjects did receive extensive instructions to attend to their arousal or benign symptoms immediately before the cheating session; they were led to believe that for them, the symptom assessment procedure was the heart of the experiment. The Control Condition data suggest instead that drawing the subject's attention to arousal-relevant symptoms without allowing him to attribute those symptoms to nonemotion sources might actually increase his feelings of emotion (indicated by relatively fewer cheaters in the arousal group than the benign group). For these cheating studies and for the attribution experiments discussed in the introduction, these results also rule out other alternative explanations based upon forewarning effects (that arousal condition instructions warn the subject of impending arousal, so that he responds less emotionally to it than benign condition subjects).

\section{Study II}

The data of Study II support the hypothesis that women apparently did not respond to the attribution manipulations in the Dienstbier and Munter (1971) study and the high stress conditions of Study II because their anxiety level was too high. There are three apparent explanations concerning the way in which high anxiety could interfere with those manipulations.

First, since more cheating occurs in the high anxiety conditions, it could be that only about $50 \%$ of such a total group of women might be tempted to cheat under any circumstances, and that most such temptable subjects do cheat when under great pressure; the always-honest second 50\% do not respond to the release offered by the arousal side effect expectations since their moral code somehow rigidly prohibits cheating. This explanation is quite complex since it required the postulation of two qualitatively different types of moral decision making, with and without emotional mediation. There is, however, no information within the data which will allow a complete negation of this explanation.

The second view is simply that it is more difficult for an individual to misattribute her arousal to a placebo when general arousal level is very high, as in the case of Conditions A and B. Again, the data do not allow acceptance or rejection of this notion.

The third view, suggested in the Introduction above, is based on the assumption that in novel situations such as presented to subjects in these stud- 
ies, all or most people are tempted. The reason then that the high stress conditions reveal no differences between arousal or benign placebo conditions is that high anxiety levels interfere with the subject's attending to the complex aspects of the study concerning the expected side effects. This interference of anxiety with complex learning and performance has been well documented (see Speilberger, 1965) in other contexts, and seems to apply to the present situation.

A second interpretation dilemma concerns the interaction of the attribution manipulation with the several emotions presumably present. Specifically, while the guilt or fear associated with cheating has been emphasized, the similar emotions of anxiety and fear induced by the "board of psychologists" threats of the stress manipulations complicate interpretation. It seems logical that if arousal were subtracted from the total situation, the emotions associated with the experimenter-induced threats should be reduced (reducing the need to cheat), but subject-induced emotions inhibiting cheating should also be reduced (thus increasing the likelihood of cheating). This analysis raises the question of whether there is evidence supporting the underlying theory of these studies, that the arousal placebo manipulation facilitates cheating by reducing the experience of emotions associated with cheating inhibitions. Evidence that the manipulation reduces emotion comes from a comparison with the manipulations of a conceptually similar cheating experiment (Schachter \& Ono, in Schachter \& Latane, 1964). In that study the reduction of general arousal through the tranquilizer chloropromazine resulted in more cheating. Also, other placebo attribution studies (particularly that of Nisbett \& Schachter (1966) in which the arousal placebo increased shock tolerance) suggest strongly that the arousal placebo manipulation does reduce general anxiety. Finally, in all the cheating research of this author, the timing of the side effects saliency manipulations (studying the side effect rating form) is such that the subject is reminded that he may begin to experience arousal (or benign) symptoms immediately before the cheating period begins. Subject comments (and an average vocabulary test score of 10) indicate that the failure experience (and hence the motivation to avoid failure) develops during the taking of the vocabulary test. Since that test is a "delay" task occurring before the subject is due to experience such symptoms, the placebo side effects are irrelevant during the acquisition of motivation to avoid failure, but quite important and salient during the period when the inhibiting emotions of fear or guilt might arise. The emotion reduction provided by the placebo manipulation is thus linked more to the emotions relevant to cheating inhibition than to those facilitating cheating.

\section{REFERENCES}

DIENSTBIER, R. A., \& MUNTER, P. O. Cheating as a function of the labeling of natural arousal. Journal of Personality and Social Psychology, 1971, 17, 208-213.

HAYS, W. L. Statistics for psychologists. New York: Holt, 1963.

MACCOBY, E. The development of sex differences. Stanford; Stanford Univ. Press, 1966.

NISBETT, R. E., \& SCHACHTER, S. Cognitive manipulation of pain. Journal of Experimental Social Psychology, 1966, 2, 227-236.

ROSS, L., RODIN, J., \& ZIMBARDO, P. G. Toward an attribution therapy; The reduction of fear through induced cognitive emotional misattribution. Journal of Personality and Social Psychology, 1969, 12, 279-288.

SCHACHTER, S., \& LATANE, B. Crime, cognition and the autonomic nervous system. In D. Levine (Ed.), Nebraska symposium on motivation. Lincoln; Univ. of Nebraska Press, 1964, 12, 221-273.

SNEDECOR, G. W. Statistical methods. Ames; Iowa State College Press, 1946.

SPIELBERGER, C. F. The effects of anxiety on complex learning and academic achievement. In Charles D. Spielberger (Ed.), Anxiety and behavior. New York; Academic Press, 1966.

STORMS, M. D., \& NISBETT, R. I. Insomnia and the attribution process. Journal of Personality and Social Psychology, 1970, 16, 329-337.

(Submitted September 1971) 